International Journal of Biomedicine | June 2019 - Volume 9, Issue Suppl_1: Abstracts From the Second Russian International Conference "Cryo-electron microscopy 2019: achievements and prospects"

POSTER ABSTRACT PRESENTATIONS

SESSION TITLE: STRUCTURE OF VIRUSES AND CHAPERONINS

DOI: 10.21103/IJBM.9.Suppl_1.P30

\title{
Abstract P-30: Structure of Bacteriophage SU10 from the Family Podoviridae
}

\author{
Marta Šiborová ${ }^{1}$, Tibor Füzik ${ }^{1}$, Martin Benešík ${ }^{2}$, Anders S. Nilson ${ }^{3}$, Pavel Plevka ${ }^{1}$
}

${ }^{1}$ Structural Virology, Central European Institute of Technology, Brno, Czech Republic; ${ }^{2}$ Laboratory of Microbial Molecular Diagnostics, Faculty of Science, Masaryk University, Czech Republic; ${ }^{3}$ Department of Molecular Biosciences, The Wenner-Gren Institute, Stockholm University, Stockholm, Sweden

Background: Bacteriophage SU10, from the family Podoviridae, infects a wide range of E. coli strains. The phage has $77 \mathrm{kbp}$ dsDNA genome, prolate capsid with the length of $135 \mathrm{~nm}$ and the diameter of $42 \mathrm{~nm}$. Contrary to what was observed in most Podoviridae phages, bacteriophage SU10 has $27 \mathrm{~nm}$ long tail. Furthermore, the baseplate of SU10 changes conformation upon attachment to the host.

Methods: We used cryo-electron microscopy and localized single particle reconstruction techniques to determine the structure of capsid, portal, tail and base plate of SU10. Furthermore, we also characterized their conformational changes associated with cell-wall binding and genome ejection.

Results: Prolate capsid is formed by 11 pentons and 110 hexons of major capsid protein. Major capsid protein has HK97 fold. The dodecameric portal complex has prolonged crown-barrel, similar to that of phage P22. Three types of fibers, all present in six copies, decorate the phage particle. Collar fibers are connected to the neck protein. Long tail fibers connected to the upper tail protein are similar to that of phage T4 and short tail fibers are positioned on bottom part of the base plate.

Conclusion: Our studies of structural changes of tail and base plate extend the current knowledge of the mechanism of host recognition and genome delivery of bacteriophage SU10.

Key Words: bacteriophage $\bullet$ localized single particle reconstruction $\bullet$ Podoviridae $\bullet$ E.coli

International Journal of Biomedicine. 2019;9 Suppl 1: S30. doi: 10.21103/IJBM.9.Suppl_1.P30

(C)2019 International Medical Research and Development Corporation 